\title{
A COMPARATIVE STUDY BETWEEN SINGLE INCISION MULTIPORT LAPAROSCOPIC APPENDICECTOMY AND CONVENTIONAL LAPAROSCOPIC APPENDECTOMY
}

\author{
Karunamoorthy Rajachidambaram¹, Dhinakaran Kaarthesan²
}

${ }^{1}$ Associate Professor, Department of General Surgery, Chennai Medical College Hospital \& Research Centre, Irungalur, Trichy. ${ }^{2}$ Associate Professor, Department of General Surgery, Chennai Medical College Hospital \& Research Centre, Irungalur, Trichy.

\section{ABSTRACT}

\section{BACKGROUND}

This is a comparative study between single incision multiport and conventional laparoscopy with triport in appendectomy.

\section{OBJECTIVES}

The objectives of this study were to compare procedures duration, postop recovery time, pain, complications, cosmesis.

\section{PLACE OF STUDY}

Department of General Surgery, Chennai Medical College Hospital and Research Centre, Irungalur, Trichy.

\section{METHOD OF COLLECTING DATA}

A randomised control study was done by alternation with sample size of 50, which divided into two groups (Study group 25 and control group 25) and study period is from April 2012 to September 2014.

\section{INCLUSION CRITERIA}

All patients with acute appendicitis diagnosed on basis of Clinical Examination, Radiological Correlation and Leucocytosis, presenting above the age of 18.

\section{EXCLUSION CRITERIA}

Patient with Phlegmon, Mass, Peri-Appendicular Abscess, Diffuse Peritonitis, Age <18, Pregnancy.

\section{RESULT}

Among 62 patients, a randomized control study of 50 patients who were divided into two groups (Study group 25 and control group 25). The study was done based on the monitoring parameters like,

1. Post-operative pain after 6 hours, 12 hours and 24 hours.

2. Duration of the procedure.

3. Surgical site infection.

4. Patient satisfaction regarding the scar.

\section{CONCLUSION}

Patient in single incision laparoscopy group show less post-operative pain in the first 6 and 12 hours compared to the conventional laparoscopy group, but no difference was noticed between the two groups after 24 hours.

No significant difference in operating times was noted between the procedures. One patient in 25 who underwent single incision laparoscopy had wound infection, but no wound complications were noted in the conventional appendicectomy group. Patients who underwent single incision laparoscopy are happier with scar when compared with conventional laparoscopy group. No difference noted in the duration of post-operative hospital stay.

\section{KEYWORDS}

Single Incision, Laparoscopic Appendicectomy, Multiport, Appendicitis, Appendectomy, Conventional Laparoscopy.

HOW TO CITE THIS ARTICLE: Rajachidambaram K, Kaarthesan D. A comparative study between single incision multiport laparoscopic appendicectomy and conventional laparoscopic appendectomy. J. Evolution Med. Dent. Sci. 2016;5(39):2372-2374, DOI: $10.14260 /$ jemds/2016/551

\section{INTRODUCTION}

Recent advances in laparoscopic instrumentations have made it possible to perform intra-abdominal operations entirely through a small incision that can be hidden within the

Financial or Other, Competing Interest: None.

Submission 29-02-2016, Peer Review 23-03-2016,

Acceptance 30-03-2016, Published 14-05-2016.

Corresponding Author:

Dr. Karunamoorthy Rajachidambaram

93G/5A, Chidambaram Nagar,

Near New Bus Stand,

Perambalur-621212.

E-mail: drkrajachidambaram@gmail.com

DOI: $10.14260 /$ jemds $/ 2016 / 551$ umbilicus, which provides better cosmetic results, decreased stay in hospital and better satisfaction to the patients.

Single incision laparoscopic surgery is a major breakthrough in minimally invasive surgeries involving access to the abdomen through a specialized port or through an incision, which appears single externally but fascially has multiple punctures.

The prospective comparisons of single incision and conventional laparoscopy are lacking. There are only ongoing trials available, some of which will be complete prior to this study's conclusion

\section{AIMS AND OBJECTIVES}

To compare the outcome of single incision multiport 
laparoscopic appendectomy vs. conventional laparoscopic appendectomy in terms of:

- Patient Recovery Time.

- Post-operative Pain.

- Wound Complications.

- Duration of the Procedure.

- Patient Satisfaction As Regards Cosmetics.

\section{MATERIALS AND METHODS}

A randomized control study was done by alternation with sample size of 50, which divided into two groups (Study group 25 and control group 25) and study period is from April 2012 to September 2014 in Chennai Medical College Hospital and Research Centre, Irungalur, Trichy.

\section{CRITERIA}

\section{Inclusion Criteria}

All patients with acute appendicitis diagnosed on basis of clinical examination, radiological correlation and leucocytosis, presenting at SRH above the age of 18.

\section{Exclusion Criteria}

Patient with Phlegmon, Mass, Peri-Appendicular Abscess, Diffuse Peritonitis, Age $<18$, Pregnancy.

\section{RESULT}

In our study only 5 patients have post-operative pain in first 6 to 12 hours after the procedure in single incision laparoscopy group. But no significant difference was noted after 24 hours.

No significant difference noted for mean operative time for single incision laparoscopy group and conventional laparoscopy group. Two patients in the single port group had an asymptomatic periumbilical haematoma. One patient had a haematoma around the surgical wound, which did not require treatment. No patient in single incision laparoscopy group had incisional hernia. Patient in single incision laparoscopy group are very happy regarding post-operative scar when compared with conventional laparoscopy group.

\section{DISCUSSION}

In our study total number of 62 patients presented with acute appendicitis in which six patients were diagnosed as appendicular mass, three patients diagnosed with appendicular abscess and three patients were lost to followup, hence they were excluded from the study. A randomized control study was done by alteration with sample size of 50 , which divided into two groups (Study group 25 and control group 25) and study period was between April 2012 to September 2014.

The following parameters were monitored following the surgery.

1. Post-operative pain after 6 hours, 12 hours and 24 .

2. Duration of the procedure.

3. Surgical site infection.

4. Patient satisfaction regarding scar.

In our study we observed less postoperative pain in first 6 and 12 hours after the procedure in single incision laparoscopy group than conventional laparoscopy group. But no significant difference was noted after 24 hours. Dolores et al(1) say that significant difference was observed for postoperative pain with less pain reported in single incision group, Jieding et al(2) says that single incision laparoscopy surgery has the advantage of less post-operative pain when compared with conventional laparoscopy group, Bong-Hyeon Kye et al (3) say that pain score on the visual analogue scale on postoperative day 1 was significantly lower in the single-incision group than in the three-port group.

There was no significant difference noted in the duration of the procedure, Jin A Lee et al(4) says that no significant difference noted for mean operative time for single incision laparoscopy group and conventional laparoscopy group. Study done by Zheng Pan et al(5) says that study did not show any difference with operative time.

One patient in single incision laparoscopy group had wound infection, which was treated with antibiotics and readmission was not required, Dolores et al(1) says that three patients in the single port group had an asymptomatic periumbilical haematoma, which did not require admission and resolve spontaneously. In conventional laparoscopy group, 2 patients had a haematoma around the surgical wound in the lower left quadrant, which did not require treatment. Study done by Zheng Pan et al(5) says that one patient in single incision laparoscopy group had incisional hernia on follow-up.

Patient in single incision laparoscopy group are very happy regarding post-operative scar when compared with conventional laparoscopy group Gasior AC et al(6) says that single incision laparoscopy surgery express superior scar assessment, Buckley FP et al(7) says that patients are more happy regarding post-operative scar when compared with conventional laparoscopy group.

\section{PROFORMA}

$\begin{array}{ll}\text { Name: } & \text { Age: } \\ & \text { Date: }\end{array}$

Address: $\quad 6$ hours $\quad 12$ hours 24

hours

Pain:

1. No Pain

2. Just noticeable Pain

3. Mild Pain

4. Uncomfortable Pain

5. Annoying Pain

6. Just Bearable

7. Moderate Pain

8. Strong Pain

9. Severe Pain

10. Horrible Pain

11. Worst Pain

Duration of Procedure

Conversion to Conventional Laparoscopy or Open Laparotomy Wound Infection:

Patient's Satisfaction as Regarding to Scar as Per a Standard Scaling System

0, 1, 2: Unhappy.

3, 4, 5, 6: Somewhat Happy.

7, 8, 9, 10: Happy.

\section{CONCLUSION}

Patient in single incision laparoscopy group show less postoperative pain in the first 6 and 12 hours compared to the conventional laparoscopy group, but no difference was noticed between the two groups after 24 hours. No significant difference in operating times was noted between the procedures. 
One patient in 25 who underwent single incision laparoscopy had wound infection, but no wound complications were noted in the conventional appendicectomy group. Patients who underwent single incision laparoscopy are happier with scar when compared with conventional laparoscopy group. No difference noted in the duration of post-operative hospital stay.

\section{REFERENCES}

1. Frutos Ma Dolores, Jesus Abrisqueta, Juan Lujan, et al. Randomized prospective study to compare laparoscopic appendectomy versus umbilical single-incision appendectomy. Ann Surg 2013;257(3):413-8.

2. Jie Ding, Yu Xia, Zhang ZM, et al. Single-incision versus conventional three-incision laparoscopic appendicectomy for appendicitis: a systematic review and meta-analysis. J Paediatr Surg 2013;48(5):1088-98.

3. Bong-Hyeon Kye, Junhyun Lee, Wook Kim, et al. Comparative study between single-incision and three-port laparoscopic appendectomy: a prospective randomized trial. Journal of Laparoendoscopic \& Advanced Surgical Techniques 2013;23(5):431-6.
4. Jin A Lee, Ki Young Sung, Jun Hyun Lee, et al. Laparoscopic appendectomy with a single incision in a single institute. The Korean Society of Coloproctology 2010;26(4):260-4.

5. Zheng Pan, Jiang XH, Zhou JH, et al. Transumbilical singleincision laparoscopic appendectomy using conventional instruments: the single working channel technique. Surgical laparoscopy, endoscopy \& percutaneous techniques 2013;23(2):208-11.

6. Gasior AC, Knott EM, Holcomb GW, et al. Patient and parental scar assessment after single incision versus standard 3-port laparoscopic appendectomy: long-term follow-up from a prospective randomized trial. J Paediatr Surg 2014;49(1):120-2. discussion 122. doi: 10.1016/j.jpedsurg.2013.09.041.

7. Buckley FP, Vassaur H, Monsivais S, et al. Single-incision laparoscopic appendectomy versus traditional three-port laparoscopic appendectomy: an analysis of outcomes at a single institution. Surg Endosc 2014;28(2):626-30. doi: 10.1007/s00464-013-3219-6. 